OPEN ACCESS

Edited by:

Oana Moldovan

Romanian Academy, Romania

Reviewed by:

Marcos Rubal,

University of Porto, Portugal

Lorena Arribas,

CONICET Instituto de Biología de

Organismos Marinos (IBIOMAR),

Argentina

*Correspondence:

Ricardo A. Scrosati

rscrosat@stfx.ca

Specialty section:

This article was submitted to Biogeography and Macroecology, a section of the journal

Frontiers in Ecology and Evolution

Received: 09 April 2020 Accepted: 13 November 2020

Published: 18 December 2020

Citation:

Scrosati RA, Freeman MJ and Ellrich JA (2020) The Subhabitat

Dependence of Biogeographic

Pattern. Front. Ecol. Evol. 8:550612.

doi: 10.3389/fevo.2020.550612

\section{The Subhabitat Dependence of Biogeographic Pattern}

\author{
Ricardo A. Scrosati ${ }^{*}$ Matthew J. Freeman and Julius A. Ellrich \\ Department of Biology, St. Francis Xavier University, Antigonish, NS, Canada
}

We introduce and test the subhabitat dependence hypothesis $(\mathrm{SDH})$ in biogeography. This hypothesis posits that biogeographic pattern within a region differs when determined with species abundance data from different subhabitat types. It stems from the notion that the main abiotic factors that drive species distribution in different subhabitat types across a biogeographic region often vary differently across space. To test the SDH, we measured the abundance of algae and sessile invertebrates in two different subhabitats (high intertidal zone and mid-intertidal zone) at eight locations along the Atlantic Canadian coast. We conducted multivariate analyses of the species abundance data to compare alongshore biogeographic pattern between both zones. For both subhabitat types, location groupings based on community similarity not always responded to geographic proximity, leading to biogeographic patchiness to some extent. Nonetheless, both biogeographic patterns were statistically unrelated, thus supporting the $\mathrm{SDH}$. This lack of concordance was most evident for southern locations, which clustered together based on high-intertidal data but showed considerable alongshore patchiness based on mid-intertidal data. We also found that the ordination pattern of these eight locations based on sea surface temperature data was significantly related to biogeographic pattern for the mid-intertidal zone but not for the high intertidal zone. This finding supports the rationale behind the $\mathrm{SDH}$ due to the longer periods of submergence experienced by the mid-intertidal zone. Overall, we conclude that biogeographic pattern within a region can depend on the surveyed subhabitat type. Thus, biological surveys restricted to specific subhabitats may not properly reveal biogeographic pattern for a biota as a whole or even just for other subhabitats. As many studies generate biogeographic information with data only for specific subhabitats, we recommend testing the SDH in other systems to determine its domain of application.

Keywords: biogeography, intertidal, invertebrates, macroalgae, benthic, subhabitat

\section{INTRODUCTION}

A central goal of biogeography is to understand species distribution patterns within biogeographic regions. A first step typically involves describing biogeographic pattern in terms of spatial groupings of locations based on species abundance data. Thus, many terrestrial and aquatic environments have been surveyed around the world. However, for reasons related to scientific interest or logistical constraints, comprehensive surveys are not always done. As a result, biogeographic patterns for regional biotas are sometimes necessarily inferred based on subsets of data. For instance, many biogeographic surveys have focused only on specific groups of organisms, such as birds 
(Hazzi et al., 2018), fish (Cowman et al., 2017), trees (Dick and Pennington, 2019), algae (Stekoll, 2019), crustaceans (Brun et al., 2020), or ants (Maravalhas and Vasconcelos, 2020), to name just a few. To some extent, however, different groups of organisms may differ in biogeographic pattern within a region, as the various drivers of species distribution may vary in importance among the groups (Qian et al., 1998; Hart and Chen, 2006; Chiu et al., 2020). Hence, distribution data for subsets of organisms may not properly reveal the biogeographic pattern for a regional biota as a whole.

Biogeographic pattern has also been determined by surveying only specific subhabitats, here understood as portions of a habitat with characteristics of their own (e.g., tree canopies in forest habitats, river beds in lotic habitats). Now, the main environmental factors that drive species distribution in different subhabitat types across a region (Pinzon et al., 2011; Whitworth et al., 2019; Greiser et al., 2020; Looby et al., 2020) often vary differently across space (e.g., soil properties affecting understory subhabitats vs. wind patterns affecting canopy subhabitats). Thus, biogeographic pattern determined with species abundance data across a region might also depend on the surveyed subhabitat type, which is hereafter referred to as the subhabitat dependence hypothesis (SDH) in biogeography. Examples of subhabitats surveyed to determine biogeographic pattern within a region are tree canopies (Pettersson et al., 1995; Boudreault et al., 2002), forest floor (Boudreault et al., 2002), phytotelmata (Trzcinski et al., 2016), and tide pools (Badger et al., 2017), among others. However, explicit tests of the SDH are largely lacking, as that kind of studies typically surveyed only one subhabitat type. When a comparison of biogeographic pattern between subhabitats from the same region was done (Boudreault et al., 2002), some differences did emerge, thereby supporting this hypothesis, but surveys were restricted to a single group of organisms (cryptogamic primary producers). Therefore, it is of interest to test the SDH by considering a wider variety of organisms from different subhabitats across a biogeographic region. The present study does so using a rocky intertidal model system.

Rocky intertidal habitats are those occurring on marine rocky shores between the highest and lowest elevations reached by tides (Menge and Branch, 2001). Because of the daily alternation of high and low tides, intertidal habitats experience alternating periods of submergence and aerial exposure every day. Due to tide dynamics, the duration of periods of aerial exposure increases markedly from low to high intertidal elevations. As a result, physiological stresses related to desiccation, thermal extremes, and osmotic potential also increase considerably with elevation. Although such changes occur gradually across elevations, average differences between coarse elevation zones (e.g., different thirds of the full vertical intertidal range) are pronounced (Eckersley and Scrosati, 2012; Watt and Scrosati, 2013; Umanzor et al., 2019). Therefore, such elevation zones represent different subhabitats especially for sessile species, because such organisms are permanently attached to the substrate and, thus, must cope with very different conditions depending on elevation zone. In this context, this study tests the $\mathrm{SDH}$ by comparing the biogeographic pattern of two elevation zones along the Atlantic Canadian coast using abundance data for sessile primary producers and consumers.

As alongshore biogeographic pattern did differ between both subhabitat types (see "Results"), we also use environmental data to explore the theory underlying the SDH. In general, temperature is a major factor influencing the distribution of species (Pörtner, 2002; Körner et al., 2016). In marine biogeography, sea surface temperature (SST) plays a particularly important role (Sanford, 2014; Henderson et al., 2017; Vallée et al., 2019). In intertidal habitats, since the duration of submergence periods increases toward lower elevations, the relationship between alongshore SST pattern and biogeographic pattern should be stronger the lower on the shore a surveyed assemblage of sessile species occurs. Therefore, this study also tests the hypothesis that alongshore SST pattern is statistically more related to alongshore biogeographic pattern for the lowest of the two surveyed elevation zones.

\section{MATERIALS AND METHODS}

We determined alongshore biogeographic pattern for the high and mid-intertidal zones (our two subhabitat types). For this purpose, we surveyed eight rocky intertidal locations spanning $415 \mathrm{~km}$ of the Atlantic Canadian coast in Nova Scotia in the summer of 2017 (Figure 1). For ease of interpretation, these locations are hereafter referred to as L1 to L8, from north to south (their names and coordinates are in Table 1). The surveyed substrate was bedrock in all cases. These locations are wave-exposed, as they face the open Atlantic Ocean without physical obstructions. Daily maximum water velocity (a proxy for wave exposure) measured with dynamometers in these intertidal habitats ranges between 6 and $12 \mathrm{~m} \mathrm{~s}^{-1}$ (Hunt and Scheibling, 2001; Scrosati and Heaven, 2007; Ellrich and Scrosati, 2017). The locations surveyed along this coast are all part of the same (coldtemperate NW Atlantic) biogeographic region (Adey and Hayek, 2005, 2011).

At each location, we measured the abundance of macroalgae and sessile invertebrates at the high and mid-intertidal zones. The high intertidal zone was the upper third of the vertical intertidal range, while the mid-intertidal zone was the middle third of the vertical intertidal range. Surveying only sessile species was particularly appropriate for this study because only local environmental conditions (e.g., high vs. mid-intertidal conditions) influence their abundance, as sessile organisms cannot move away once their reproductive propagules settle on the substrate. On the contrary, mobile intertidal species (snails, crabs, etc.) move up and down the shore with the daily changes in abiotic conditions at low tide (hot-vs-cold and dryvs-rainy weather), which makes their abundance less responsive to the average environmental differences that characterize coarse elevation zones (Burrows and Hughes, 1989).

At each location, we measured species abundance in 10 quadrats $(20 \mathrm{~cm} \times 20 \mathrm{~cm})$ placed haphazardly following the coastline at each of the high and mid-intertidal zones, avoiding tide pools. The sampling device was a metallic frame with 


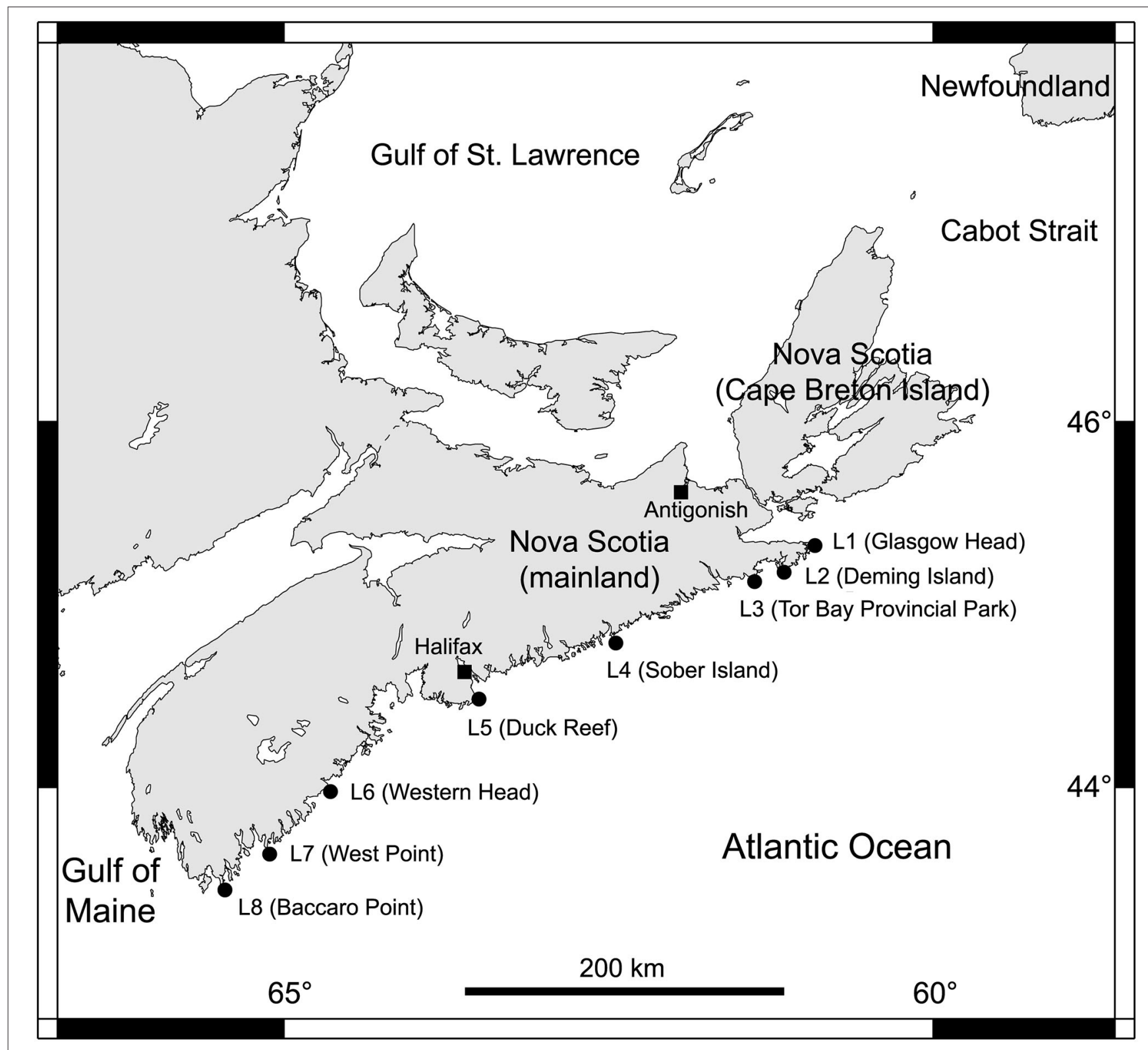

FIGURE 1 | Map showing the eight wave-exposed rocky intertidal locations surveyed along the Atlantic Canadian coast.

100 square subdivisions delimited with monofilament line. Abundance may be measured with different metrics in ecology (Veiga et al., 2020). We quantified abundance as percent cover, a non-destructive approach normally employed for sessile intertidal species (Menge et al., 2003; Catalán et al., 2020) that is also adequate for clonal seaweeds that grow in dense stands, for which the identification of individuals (as opposed to ramets) is very difficult (Scrosati, 2005). For each quadrat, we determined the percent cover of a species as the number of subdivisions covered by half or more by that species when viewing the quadrat perpendicularly to the substrate at low tide. When there were macroalgal canopies covering understory organisms, we first measured the percent cover of the canopy species and then the cover of the understory species after carefully moving away the canopies. If a species was present in a quadrat but did not cover any subdivision by half or more, we recorded its percent cover for that quadrat as $0.5 \%$. We used field guides and taxonomic keys to identify the organisms (Gibson, 2003; Sept, 2008; Mathieson and Dawes, 2017). The list of identified species and their average abundance per location are provided in Table 2. The two blue mussel species from this coast (Mytilus edulis and $M$. trossulus) can only be identified with genetic markers (Comesaña et al., 1999), so Table 2 refers to them as Mytilus spp., although genetic samples from wave-exposed intertidal habitats from this coast have shown a predominance of $M$. trossulus (80$85 \%$ ) over M. edulis (Tam and Scrosati, 2011). The full data set on species abundance is available from the figshare online repository (Scrosati and Ellrich, 2020a). 
TABLE 1 | Basic information about the eight wave-exposed locations surveyed for this study.

\begin{tabular}{|c|c|c|}
\hline Location code & $\begin{array}{l}\text { Location name } \\
\text { (geographic coordinates) }\end{array}$ & $\begin{array}{l}\text { Closest location with tide } \\
\text { data (geographic } \\
\text { coordinates) }\end{array}$ \\
\hline L1 & $\begin{array}{l}\text { Glasgow Head (45.3203, } \\
-60.9592)\end{array}$ & Canso $(45.3500,-61.0000)$ \\
\hline L2 & $\begin{array}{l}\text { Deming Island (45.2121, } \\
-61.1738)\end{array}$ & $\begin{array}{l}\text { Whitehead (45.2333, } \\
-61.1833)\end{array}$ \\
\hline L3 & $\begin{array}{l}\text { Tor Bay Provincial Park } \\
(45.1823,-61.3553)\end{array}$ & $\begin{array}{l}\text { Larry's River (45.2167, } \\
-61.3833)\end{array}$ \\
\hline$\llcorner 4$ & $\begin{array}{l}\text { Sober Island (44.8223, } \\
-62.4573)\end{array}$ & $\begin{array}{l}\text { Port Bickerton (45.1000, } \\
-61.7333)\end{array}$ \\
\hline L5 & $\begin{array}{l}\text { Duck Reef (44.4913, } \\
-63.5270)\end{array}$ & $\begin{array}{l}\text { Sambro (44.4833, } \\
-63.6000)\end{array}$ \\
\hline L6 & $\begin{array}{l}\text { Western Head (43.9896, } \\
\text {-64.6607) }\end{array}$ & $\begin{array}{l}\text { Liverpool (44.0500, } \\
-64.7167)\end{array}$ \\
\hline L7 & $\begin{array}{l}\text { West Point (43.6533, } \\
-65.1309)\end{array}$ & $\begin{array}{l}\text { Lockeport (43.7000, } \\
-65.1167)\end{array}$ \\
\hline L8 & $\begin{array}{l}\text { Baccaro Point (43.4496, } \\
-65.4697)\end{array}$ & $\begin{array}{l}\text { Ingomar (43.5667, } \\
-65.3333)\end{array}$ \\
\hline
\end{tabular}

We measured SST during the months when most of the growth in cold-temperate intertidal sessile species typically occurs (May to August). Using SST data for more than 1 year is advantageous because sessile communities are the result of years of thermal influences (Schiel et al., 2016). Thus, we measured SST at each intertidal location every day during the months of May, June, July, and August for a period that started on 1 May 2015 and ended on 21 June 2017, before we measured species abundance. We measured SST with submersible loggers (HOBO Pendant logger, Onset Computer, Bourne, MA, USA) that were permanently attached to the substrate at the boundary between the high and mid-intertidal zones using eye screws and plastic cable ties, allowing almost no contact between the loggers and the substrate. The loggers recorded temperature every $30 \mathrm{~min}$. From the resulting time series of temperature, we extracted the values of daily SST, considered as the temperature recorded closest to the time of the highest tide of each day, when the loggers were fully submerged in seawater. We determined the time of such tides using information (Tide and Current Predictor, 2020) for the tide reference stations that are closest to our surveyed intertidal locations (Table 1). The full SST data set is also available from the figshare online repository (Scrosati et al., 2020).

We determined biogeographic pattern separately for the high and mid-intertidal zones through the multivariate ordination of locations based on their species abundance data (Clarke et al., 2014). All of the analyses reported in this paper were done with Primer 7 with Permanova+ (Anderson et al., 2008; Clarke and Gorley, 2015). For each elevation zone, we first calculated BrayCurtis similarity for each possible pair of quadrats and, based on that information, we then calculated the multivariate distance for each possible pair of location centroids. To determine biogeographic pattern for each intertidal zone, we ran non-metric multidimensional scaling (NMDS) to produce an ordination of the corresponding eight location centroids with overlayed clusters. To test the SDH, we statistically compared the two resulting biogeographic patterns with a correlative RELATE test followed by 5,000 permutations for significance testing. To examine possible associations with the SST data, we first ran NMDS to produce a multivariate ordination of the eight locations based on their SST data and Euclidean distances between locations. Then, separately for the high and mid-intertidal zones, we used the RELATE technique to test if the centroid-based biogeographic pattern was statistically related to the SST-based ordination pattern, using 5,000 permutations for significance testing for both tests.

\section{RESULTS}

We identified 22 sessile species in total, 12 of which occurred at both elevation zones, one only at the high intertidal zone, and nine only at the mid-intertidal zone (Table 2). Thus, the high intertidal zone hosted 13 species (eight macroalgae and five sessile invertebrates) while the mid-intertidal zone exhibited 21 species (17 macroalgae and four sessile invertebrates).

The multivariate ordination of the eight locations based on species abundance data revealed biogeographic structure along the coast for both the high and mid-intertidal zones (Figure 2). However, the alongshore biogeographic pattern was not the same for both zones. At the high intertidal zone, there was patchiness along the northern half of the studied coastal range, as locations L1 and L3 and locations L2 and L4 formed two distinctive clusters, while the four locations on the southern half of the studied coastal range (L5 to L8) formed a tight third cluster (Figure 2A). At the mid-intertidal zone, the biogeographic pattern along the northern half of the studied coastal range was not too different from that at the high intertidal zone, as L2 and L4 also clustered together while L1 and L3 also differed from that cluster, although differing between themselves more. On the southern half of the studied coastal range, however, there were considerably higher differences among the locations, as L6 differed from an L5-L7 cluster while L8 differed markedly actually from all other locations (Figure 2B). Overall, alongshore biogeographic pattern differed between the high and midintertidal zones, as both patterns were statistically unrelated (RELATE test's $r=0.268, p=0.179$ ). On the other hand, the SSTbased ordination pattern of locations was significantly related to the biogeographic pattern for locations only for the midintertidal zone $(r=0.442, p=0.022)$, as there was no significant relationship for the high intertidal zone $(r=0.271, p=0.113)$.

\section{DISCUSSION}

The biogeographic comparison of two intertidal elevation zones along the Nova Scotia coast has supported the SDH, as both subhabitat types differed in alongshore biogeographic pattern. An important implication of these findings is that, in terms of spatial groupings of surveyed locations, biogeographic pattern for a regional biota as a whole may not be adequately inferred from data measured for only one subhabitat type. This is a potentially relevant concept for biogeography because, for a 
TABLE 2 | Abundance of sessile species (mean percent cover, with SE in parenthesis) found at the high and mid-intertidal zones at each of the eight surveyed intertidal locations (L1 to L8).

\begin{tabular}{|c|c|c|c|c|c|c|c|c|}
\hline \multicolumn{9}{|c|}{ High intertidal zone } \\
\hline Taxon & L1 & L2 & L3 & L4 & L5 & L6 & L7 & L8 \\
\hline \multicolumn{9}{|l|}{ Macroalgae } \\
\hline Chondrus crispus & $0.70(0.70)$ & - & $0.30(0.21)$ & $6.20(3.13)$ & $5.10(2.00)$ & $1.10(0.80)$ & $21.80(5.25)$ & 8.05 (2.68) \\
\hline Corallina officinalis & - & - & - & $0.30(0.21)$ & $0.10(0.10)$ & - & $0.05(0.05)$ & $0.20(0.20)$ \\
\hline Elachista fucicola & $1.35(0.74)$ & $5.70(1.37)$ & $2.50(1.07)$ & $1.80(0.76)$ & $13.40(1.77)$ & $11.70(1.86)$ & $6.60(1.25)$ & $8.60(2.12)$ \\
\hline Fucus vesiculosus & $9.70(4.65)$ & $88.30(2.89)$ & $30.10(11.66)$ & $97.20(1.52)$ & $87.50(3.44)$ & $63.8(7.04)$ & $85.20(5.25)$ & $52.60(8.25)$ \\
\hline Hildenbrandia rubra & $3.30(0.82)$ & $3.95(0.82)$ & $9.00(2.67)$ & $2.07(1.04)$ & $19.00(2.93)$ & $22.30(4.96)$ & $10.90(2.20)$ & $10.70(2.52)$ \\
\hline Lithothamnion glaciale & - & - & - & $0.30(0.21)$ & - & $0.20(0.13)$ & $2.15(0.94)$ & $3.70(1.27)$ \\
\hline Porphyra umbilicalis & - & - & - & - & - & $2.35(0.94)$ & - & - \\
\hline Scytosiphon lomentaria & - & - & - & $0.10(0.10)$ & - & $0.10(0.10)$ & - & - \\
\hline \multicolumn{9}{|l|}{ Invertebrates } \\
\hline Dynamena pumila & - & $1.55(0.71)$ & - & - & - & - & $0.20(0.11)$ & - \\
\hline Modiolus modiolus & - & - & - & - & - & - & $0.10(0.10)$ & - \\
\hline Mytilus spp. & $0.15(0.08)$ & $2.25(0.66)$ & $0.70(0.52)$ & $0.25(0.08)$ & $10.45(5.25)$ & $13.80(3.46)$ & $7.90(1.60)$ & $4.00(1.62)$ \\
\hline Semibalanus balanoides & $24.20(6.54)$ & $22.40(2.82)$ & $34.90(9.90)$ & $4.13(0.69)$ & $2.90(0.69)$ & $8.30(3.37)$ & $2.60(0.58)$ & $1.60(0.54)$ \\
\hline Urticina felina & - & - & - & - & - & - & $0.05(0.05)$ & - \\
\hline
\end{tabular}

Mid-intertidal zone

\begin{tabular}{|c|c|c|c|c|c|c|c|c|}
\hline Taxon & L1 & L2 & L3 & L4 & L5 & L6 & L7 & L8 \\
\hline \multicolumn{9}{|l|}{ Macroalgae } \\
\hline Chondrus crispus & $3.70(1.63)$ & $9.40(2.70)$ & $5.40(3.30)$ & $18.10(6.75)$ & $37.80(4.83)$ & $5.20(2.22)$ & $63.30(8.13)$ & $89.50(5.81)$ \\
\hline Chordaria flagelliformis & - & - & - & - & $0.70(0.52)$ & - & - & - \\
\hline Cladophora rupestris & - & - & - & $1.50(0.86)$ & - & - & - & - \\
\hline Codium fragile & $0.10(0.10)$ & - & $2.40(0.65)$ & $0.25(0.20)$ & $1.20(0.36)$ & - & - & - \\
\hline Colpomenia peregrina & - & - & - & - & - & - & - & $0.70(0.52)$ \\
\hline Corallina officinalis & $0.10(0.07)$ & $1.75(0.78)$ & $0.45(0.40)$ & $4.40(2.07)$ & $4.55(1.38)$ & $0.50(0.40)$ & $2.55(0.93)$ & $1.50(0.87)$ \\
\hline Elachista fucicola & $54.00(8.84)$ & $12.80(2.51)$ & $18.90(8.10)$ & $16.70(4.163)$ & $13.10(3.80)$ & $11.50(2.10)$ & $19.20(6.07)$ & $3.90(1.65)$ \\
\hline Fucus vesiculosus & $18.60(8.75)$ & $100(0)$ & $11.40(3.82)$ & $76.50(9.14)$ & $49.50(9.81)$ & $73.70(6.45)$ & $46.20(12.50)$ & $2.10(1.79)$ \\
\hline Hildenbrandia rubra & $10.00(4.44)$ & $12.10(2.64)$ & $18.20(4.44)$ & $20.10(6.42)$ & $13.90(4.17)$ & $38.70(11.84)$ & $5.70(2.37)$ & - \\
\hline Laminaria digitata & - & $0.10(0.10)$ & - & - & - & - & - & - \\
\hline Leathesia difformis & - & - & - & - & $0.10(0.07)$ & - & - & - \\
\hline Lithothamnion glaciale & $0.10(0.10)$ & - & - & $0.30(0.21)$ & $0.30(0.21)$ & $7.80(4.07)$ & $3.10(0.95)$ & - \\
\hline Palmaria palmata & - & - & - & $0.10(0.10)$ & - & $2.30(1.15)$ & - & - \\
\hline Polysiphonia stricta & - & - & - & - & - & $4.90(2.19)$ & $3.30(1.69)$ & - \\
\hline Porphyra umbilicalis & - & - & $7.80(2.15)$ & - & $0.70(0.25)$ & $2.20(0.98)$ & $0.10(0.10)$ & - \\
\hline Scytosiphon lomentaria & $6.10(2.27)$ & - & $2.30(0.78)$ & - & $0.40(0.40)$ & - & $0.20(0.20)$ & - \\
\hline Ulva lactuca & - & - & - & - & $0.30(0.21)$ & - & - & $0.20(0.20)$ \\
\hline \multicolumn{9}{|l|}{ Invertebrates } \\
\hline Dynamena pumila & - & - & - & $0.10(0.10)$ & - & - & $0.50(0.40)$ & - \\
\hline Mytilus spp. & $1.15(0.36)$ & $3.60(0.64)$ & $1.80(1.39)$ & $0.40(0.10)$ & $1.90(0.56)$ & - & $3.95(1.43)$ & $11.20(4.51)$ \\
\hline Semibalanus balanoides & $4.35(2.37)$ & $33.60(4.40)$ & $18.85(6.49)$ & $3.35(0.84)$ & $0.50(0.11)$ & $0.15(0.08)$ & $0.95(0.58)$ & - \\
\hline Urticina felina & - & - & - & - & - & - & $0.45(0.30)$ & - \\
\hline
\end{tabular}

number of terrestrial and aquatic systems, biogeographic pattern within a region has been determined exclusively based on data for specific subhabitats (Pettersson et al., 1995; Boudreault et al., 2002; Trzcinski et al., 2016; Badger et al., 2017). While such an approach was appropriate for the particular goals of those studies, ultimately it is important to recognize that biogeographic pattern for the entire biota might not be properly inferred from such surveys. Therefore, an important next step in this research line would be to test the SDH in other systems to identify factors that might influence its domain of application. In this sense, 


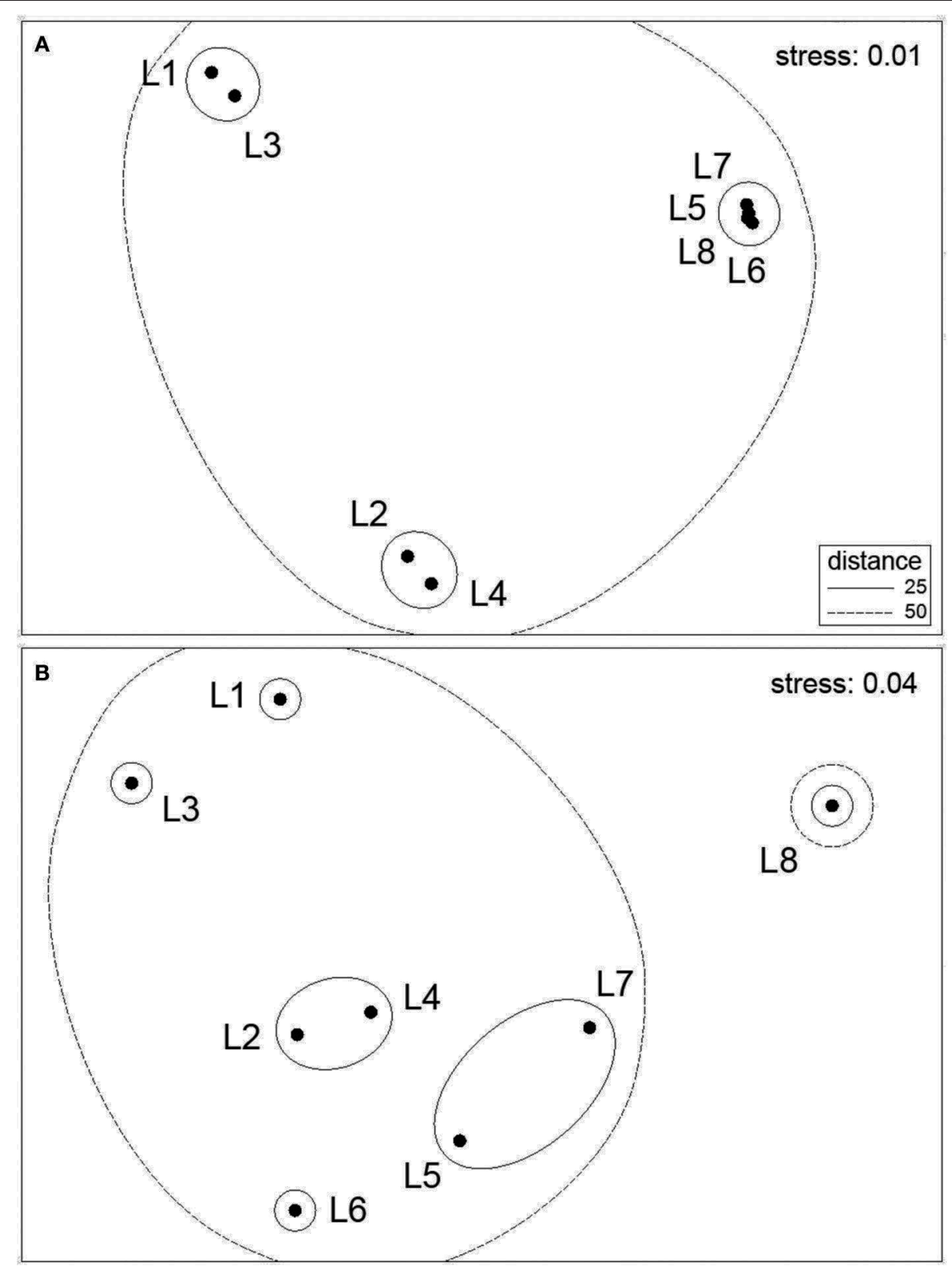

FIGURE 2 | NMDS ordination plots of the eight location centroids with overlayed clusters for the (A) high intertidal zone and (B) mid-intertidal zone.

a comparison of biogeographic pattern between two terrestrial subhabitats (tree canopies vs. forest floor) based on data for cryptogams has also revealed a difference in pattern (Boudreault et al., 2002), suggesting that the SDH might be applicable to a variety of systems.

The SDH stems from the notion that the abiotic factors that primarily drive species distribution for different subhabitat types across a biogeographic region (Pinzon et al., 2011; Whitworth et al., 2019; Greiser et al., 2020; Looby et al., 2020) often vary differently across space. SST is an important driver of marine species distribution in general (Sanford, 2014; Henderson et al., 2017; Vallée et al., 2019) but, in intertidal habitats, this factor is expected to have a larger influence on the distribution of sessile species the longer time they spend underwater, which is mainly determined by their elevation on the shore (Menge and Branch, 2001). Thus, the occurrence of a relationship between the SST-based ordination of locations and biogeographic pattern for the mid-intertidal zone but not for the high intertidal zone lends support to the rationale behind the SDH. These are valuable results because they are based on in situ SST data, as opposed to satellite SST data, which are often less accurate for coastal environments (Smale and Wernberg, 2009) and sometimes even unavailable for some days. 
Besides its suitability to test the SDH, our data set has also revealed species abundance trends in wave-exposed intertidal habitats along the Nova Scotia coast (Table 2). Such patterns had not been previously described and, thus, can be a useful reference for future studies on biological invasions, environmental impacts, or species distribution changes resulting from climate change. Complex alongshore community patterns have emerged, including species that predominate on northern (the barnacle Semibalanus balanoides) or southern (the red alga Chondrus crispus) locations and species that have a more uniform, albeit patchy, distribution along the coast (the brown alga Fucus vesiculosus). Identifying the abiotic and biotic drivers of those alongshore changes necessarily remained beyond this study's reach. To address that goal, it would be necessary to have location-specific information on, for example, nutrient concentration (Kraufvelin et al., 2006; Vinueza et al., 2014), influences of upwelling and surf zone on planktonic food supply and larval transport (Schiel, 2004; Menge and Menge, 2013; Shanks and Morgan, 2018), benthic disturbance (Cimon and Cusson, 2018), and interspecific interactions (Menge, 1995; Harley, 2011). However, the Nova Scotia coast lags behind other coasts of the world on such details. Information on those factors is becoming available for the Nova Scotia coast (Petzold and Scrosati, 2014, Ellrich and Scrosati, 2016, Scrosati and Ellrich, 2018, 2020b,c), which should thus stimulate further studies to ultimately explain the observed patterns of alongshore species distribution.

In summary, the present study shows that biogeographic pattern determined with species abundance data across a region can depend on the surveyed subhabitat type. Thus, biological surveys restricted to specific subhabitats may not properly reveal spatial groupings of locations for a biota as a whole or even just for other subhabitats. Having reliable information on biogeographic pattern is not only important for the advancement of biogeography as a discipline, but also for applied purposes such as the design and management of protected areas (Reiss et al., 2009; Sayre et al., 2020; van Niekerk et al., 2020). As noted

\section{REFERENCES}

Adey, W. H., and Hayek, L. A. C. (2005). The biogeographic structure of the western North Atlantic rocky intertidal. Cryptogam. Algol. 26, 35-66.

Adey, W. H., and Hayek, L. A. C. (2011). Elucidating marine biogeography with macrophytes: quantitative analysis of the North Atlantic supports the thermogeographic model and demonstrates a distinct Subarctic region in the northwestern Atlantic. Northeast. Nat. 18, 1-128. doi: 10.1656/045.018.m801

Anderson, M. J., Gorley, R. N., and Clarke, K. R. (2008). PERMANOVA+ for PRIMER: Guide to Software and Statistical Methods. Lutton: PRIMER-E.

Badger, M., Tucker, S. J., Grattepanche, J. D., and Katz, L. A. (2017). Rapid turnover of ciliate community members in New England tide pools. Aquat. Microb. Ecol. 80, 43-54. doi: 10.3354/ame01839

Boudreault, C., Bergeron, Y., Gauthier, S., and Drapeau, P. (2002). Bryophyte and lichen communities in mature to old-growth stands in eastern boreal forests of Canada. Can. J. Forest Res. 32, 1080-1093. doi: 10.1139/x02-027

Brun, A. A., Griotti, M., Roig-Juñent, S. A., and Acha, M. E. (2020). Biogeographical patterns and areas of endemism for the Magellan region above, there is a wealth of biogeographic information based on data only for specific subhabitats, and such studies will likely continue to be done. It would thus be useful to investigate how predictive biogeographic information for different subhabitats can be for other subhabitats or for whole biotas. Therefore, we recommend to test the $\mathrm{SDH}$ in other systems to determine its domain of application.

\section{DATA AVAILABILITY STATEMENT}

The data sets used for this study are freely available from the figshare online repository: https://doi.org/10.6084/m9.figshare. 12058821.v1 (Scrosati and Ellrich, 2020a) and https://doi.org/10. 6084/m9.figshare.12058962.v1 (Scrosati et al., 2020).

\section{AUTHOR CONTRIBUTIONS}

RAS conceived the idea, designed the study, and wrote the manuscript. JAE and RAS collected the field data. MJF and RAS analyzed the data. All authors contributed to the article and approved the submitted version.

\section{FUNDING}

This study was funded by research grants from the Natural Sciences and Engineering Research Council of Canada (NSERC Discovery Grant \#311624) and the Canada Foundation for Innovation (CFI Leaders Opportunity Grant \#202034) awarded to RAS, by a Nova Scotia Graduate Scholarship (no number) awarded to MJF, and by a postdoctoral fellowship from the German Academic Exchange Service (DAAD \#91617093) awarded to JAE.

\section{ACKNOWLEDGMENTS}

We thank Carmen Denfeld, Meredith Karcz, and Willy Petzold for field assistance and three reviewers for constructive comments on our study.

based on the distribution of crustacean species (Amphipoda, Copepoda, and Euphausiacea). Polar Biol. 43, 237-250. doi: 10.1007/s00300-02002626-1

Burrows, M. T., and Hughes, R. N. (1989). Natural foraging of the dogwhelk, Nucella lapillus (Linnaeus); the weather and whether to feed. J. Molluscan Stud. 55, 285-295. doi: 10.1093/mollus/55.2.285

Catalán, A. M., Valdivia, N., and Scrosati, R. A. (2020). Interhemispheric comparison of scale-dependent spatial variation in the structure of intertidal rocky-shore communities. Ecosphere 11:e03068. doi: 10.1002/ecs2.3068

Chiu, W. T. R., Yasuhara, M., Cronin, T. M., Hunt, G., Gemery, L., and Wei, C. L. (2020). Marine latitudinal diversity gradients, niche conservatism, and out of the tropics and Arctic: climatic sensitivity of small organisms. J. Biogeogr. 47, 817-828. doi: 10.1111/jbi.13793

Cimon, S., and Cusson, M. (2018). Impact of multiple disturbances and stress on the temporal trajectories and resilience of benthic intertidal communities. Ecosphere 9:e02467. doi: 10.1002/ecs2.2467

Clarke, K. R., and Gorley, R. N. (2015). PRIMER v7: User Manual. Lutton: PRIMER-E. 
Clarke, K. R., Gorley, R. N., Somerfield, P. J., and Warwick, R. M. (2014). Change in Marine Communities: An Approach to Statistical Analysis and Interpretation. Lutton: PRIMER-E.

Comesaña, A. S., Toro, J. E., Innes, D. J., and Thompson, R. J. (1999). A molecular approach to the ecology of a mussel (Mytilus edulis - M. trossulus) hybrid zone on the east coast of Newfoundland, Canada. Mar. Biol. 133, 213-221. doi: $10.1007 /$ s002270050460

Cowman, P. F., Parravicini, V., Kulbicki, M., and Floeter, S. R. (2017). The biogeography of tropical reef fishes: endemism and provinciality through time. Biol. Rev. 92, 2112-2130. doi: 10.1111/brv.12323

Dick, C. W., and Pennington, R. T. (2019). History and geography of Neotropical tree diversity. Annu. Rev. Ecol. Evol. Syst. 50, 279-301. doi: 10.1146/annurev-ecolsys-110617-062314

Eckersley, L. K., and Scrosati, R. A. (2012). Temperature, desiccation, and species performance trends along an intertidal elevation gradient. Curr. Dev. Oceanogr. 5, 59-73. doi: 10.31230/osf.io/y9ph3

Ellrich, J. A., and Scrosati, R. A. (2016). Water motion modulates predator nonconsumptive limitation of prey recruitment. Ecosphere 7:e01402. doi: $10.1002 /$ ecs 2.1402

Ellrich, J. A., and Scrosati, R. A. (2017). Maximum Water Velocities in WaveExposed Rocky Intertidal Habitats From Deming Island, Atlantic Coast of Nova Scotia, Canada. Pangaea Digital Repository. Available online at: http://doi.org/ 10.1594/pangaea.880722

Gibson, M. A. (2003). Seashores of the Maritimes. Halifax: Nimbus Publishing.

Greiser, C., Ehrlén, J., Meineri, E., and Hylander, K. (2020). Hiding from the climate: characterizing microrefugia for boreal forest understory species. Global Change Biol. 26, 471-483. doi: 10.1111/gcb.14874

Harley, C. D. G. (2011). Climate change, keystone predation, and biodiversity loss. Science 334, 1124-1127. doi: 10.1126/science.1210199

Hart, S. A., and Chen, H. Y. H. (2006). Understory vegetation dynamics of North American boreal forests. Crit. Rev. Plant Sci. 25, 381-397. doi: 10.1080/07352680600819286

Hazzi, N. A., Moreno, J. S., Ortiz-Movliav, C., and Palacio, R. D. (2018). Biogeographic regions and events of isolation and diversification of the endemic biota of the tropical Andes. Proc. Natl. Acad. Sci. U.S.A. 115, 7985-7990. doi: 10.1073/pnas.1803908115

Henderson, M. E., Mills, K. E., Thomas, A. C., Pershing, A. J., and Nye, J. A. (2017). Effects of spring onset and summer duration on fish species distribution and biomass along the northeast United States continental shelf. Rev. Fish Biol. Fish. 27, 411-424. doi: 10.1007/s11160-017-9487-9

Hunt, H. L., and Scheibling, R. E. (2001). Patch dynamics of mussels on rocky shores: integrating process to understand pattern. Ecology 82, 3213-3231. doi: 10.1890/0012-9658(2001)082[3213:PDOMOR]2.0.CO;2

Körner, C., Basler, D., Hoch, G., Kollas, C., Lenz, A., Randin, C. F., et al. (2016). Where, why and how? Explaining the low-temperature range limits of temperate tree species. J. Ecol. 104, 1076-1088. doi: 10.1111/1365-2745. 12574

Kraufvelin, P., Moy, F. E., Christie, H., and Bokn, T. L. (2006). Nutrient addition to experimental rocky shore communities revisited: delayed responses, rapid recovery. Ecosystems 9, 1076-1093. doi: 10.1007/s10021-005-0188-1

Looby, C. I., Hollenbeck, E. C., and Treseder, K. K. (2020). Fungi in the canopy: how soil fungi and extracellular enzymes differ between canopy and ground soils. Ecosystems 23, 768-782. doi: 10.1007/s10021-019-00439-w

Maravalhas, J. B., and Vasconcelos, H. L. (2020). Ant diversity in Neotropical savannas: hierarchical processes acting at multiple spatial scales. J. Anim. Ecol. 89, 412-422. doi: 10.1111/1365-2656.13111

Mathieson, A. C., and Dawes, C. J. (2017). Seaweeds of the Northwest Atlantic. Amherst: University of Massachusetts Press.

Menge, B. A. (1995). Indirect effects in marine rocky intertidal interaction webs: patterns and importance. Ecol. Monogr. 65, 21-74. doi: 10.2307/2937158

Menge, B. A., and Branch, G. M. (2001). "Rocky intertidal communities," in Marine Community Ecology, eds M. D. Bertness, S. D. Gaines, and M. H. Hay (Sunderland, MA: Sinauer), 221-251.

Menge, B. A., Lubchenco, J., Bracken, M. E. S., Chan, F., Foley, M. M., Freidenburg, T. L., et al. (2003). Coastal oceanography sets the pace of rocky intertidal community dynamics. Proc. Natl. Acad. Sci. U.S.A. 100, 12229-12234. doi: $10.1073 /$ pnas. 1534875100
Menge, B. A., and Menge, D. N. L. (2013). Dynamics of coastal meta-ecosystems: the intermittent upwelling hypothesis and a test in rocky intertidal regions. Ecol. Monogr. 83, 283-310. doi: 10.1890/12-1706.1

Pettersson, R., Ball, J., Renhorn, K. E., Esseen, P. A., and Sjoberg, K. (1995). Invertebrate communities in boreal forest canopies as influenced by forestry and lichens with implications for passerine birds. Biol. Cons. 74, 57-63. doi: 10.1016/0006-3207(95)00015-V

Petzold, W., and Scrosati,. R. A. (2014). Differential recolonization of Atlantic intertidal habitats after disturbance reveals potential bottomup community regulation. F1000 Res. 3:247. doi: 10.12688/f1000research. 5545.1

Pinzon, J., Spence, J. R., and Langor, D. W. (2011). Spider assemblages in the overstory, understory, and ground layers of managed stands in the western boreal mixedwood forest of Canada. Environ. Entomol. 40, 797-808. doi: $10.1603 /$ EN11081

Pörtner, H. O. (2002). Climate variations and the physiological basis of temperature-dependent biogeography: systemic to molecular hierarchy of thermal tolerance in animals. Comp. Biochem. Physiol. A Mol. Integr. Physiol. 132, 739-761. doi: 10.1016/S1095-6433(02)00045-4

Qian, H., Klinka, K., and Kayahara, G. J. (1998). Longitudinal patterns of plant diversity in the North American boreal forest. Plant Ecol. 138, 161-178. doi: 10.1023/A:1009756318848

Reiss, H., Degraer, S., Duineveld, G. C. A., Kröncke, I., Aldridge, J., Craeymeersch, J. A., et al. (2009). Spatial patterns of infauna, epifauna, and demersal fish communities in the North Sea. ICES J. Mar. Sci. 67, 278-293. doi: 10.1093/icesjms/fsp253

Sanford, E. (2014). "The biogeography of marine communities," in Marine Community Ecology and Conservation, eds M. D. Bertness, J. F. Bruno, B. R. Silliman, and J. J. Stachowicz (Sunderland, MA: Sinauer), 131-163.

Sayre, R., Karagulle, D., Frye, C., Boucher, T., Wolff, N. H., Breyer, S., et al. (2020). An assessment of the representation of ecosystems in global protected areas using new maps of world climate regions and world ecosystems. Global Ecol. Cons. 21:e00860. doi: 10.1016/j.gecco.2019.e00860

Schiel, D. R. (2004). The structure and replenishment of rocky shore intertidal communities and biogeographic comparisons. J. Exp. Mar. Biol. Ecol. 300, 309-342. doi: 10.1016/j.jembe.2004.01.001

Schiel, D. R., Lilley, S. A., South, P. M., and Coggins, J. H. J. (2016). Decadal changes in sea surface temperature, wave forces, and intertidal structure in New Zealand. Mar. Ecol. Prog. Ser. 548, 77-95. doi: 10.3354/meps11671

Scrosati, R. (2005). Review of studies on biomass-density relationships (including self-thinning lines) in seaweeds: main contributions and persisting misconceptions. Phycol. Res. 53, 224-233. doi: 10.1111/j.1440-1835.2005.tb00375.x

Scrosati, R., and Heaven, C. (2007). Spatial trends in community richness, diversity, and evenness across rocky intertidal environmental stress gradients in eastern Canada. Mar. Ecol. Prog. Ser. 342, 1-14. doi: 10.3354/meps 342001

Scrosati, R. A., and Ellrich,. J. A. (2018). Benthic-pelagic coupling and bottomup forcing in rocky intertidal communities along the Atlantic Canadian coast. Ecosphere 9:e02229. doi: 10.1002/ecs2.2229

Scrosati, R. A., and Ellrich,. J. A. (2020a). Abundance of Sessile Species in Wave-Exposed Intertidal Habitats Along the Atlantic Canadian Coast. Figshare Digital Repository. Available online at: https://doi.org/10.6084/m9.figshare. 12372014.v1

Scrosati, R. A., and Ellrich, J. A. (2020b). Marked contrast in winddriven upwelling on the southeastern Nova Scotia coast in July of two years differing in ENSO conditions. Oceanol. Hydrobiol. Stud. 49, 81-87. doi: 10.1515/ohs-2020-0008

Scrosati, R. A., and Ellrich, J. A. (2020c). Latitudinal and seasonal changes in intertidal sea surface temperature along the Atlantic coast of Nova Scotia, Canada. Front. Mar. Sci. 7:592. doi: 10.3389/fmars.2020.00592

Scrosati, R. A., Ellrich, J. A., and Freeman, M. J. (2020). Daily SST at 8 WaveExposed Intertidal Locations Along the Atlantic Canadian Coast. Figshare Digital Repository. Available online at: https://doi.org/10.6084/m9.figshare. 12374258.v1

Sept, J. D. (2008). A Photographic Guide to Seashore Life in the North Atlantic: Canada to Cape Cod. Princeton, NJ: Princeton University Press. 
Shanks, A. L., and Morgan, S. G. (2018). Testing the intermittent upwelling hypothesis: upwelling, downwelling, and subsidies to the intertidal zone. Ecol. Monogr. 88, 22-35. doi: 10.1002/ecm.1281

Smale, D. A., and Wernberg, T. (2009). Satellite-derived SST data as a proxy for water temperature in nearshore benthic ecology. Mar. Ecol. Prog. Ser. 387, 27-37. doi: 10.3354/meps08132

Stekoll, M. S. (2019). The seaweed resources of Alaska. Bot. Mar. 62, 227-235. doi: 10.1515/bot-2018-0064

Tam, J. C., and Scrosati, R. A. (2011). Mussel and dogwhelk distribution along the NW Atlantic coast: testing predictions derived from the abundantcentre model. J. Biogeogr. 38, 1536-1545. doi: 10.1111/j.1365-2699.2011. 02498.x

Tide and Current Predictor (2020). Tidal Height and Current Site Selection. Available online at: http://tbone.biol.sc.edu/tide/index.html (accessed August 10, 2020).

Trzcinski, M. K., Srivastava, D. S., Corbara, B., Dézerald, O., Leroy, C., Carrias, J. F., et al. (2016). The effects of food web structure on ecosystem function exceeds those of precipitation. J. Anim. Ecol. 85, 1147-1160. doi: 10.1111/1365-2656.12538

Umanzor, S., Ladah, L., Calderón-Aguilera, L. E., and Zertuche-González, J. A. (2019). Testing the relative importance of intertidal seaweeds as ecosystem engineers across tidal heights. J. Exp. Mar. Biol. Ecol. 511, 100-107. doi: 10.1016/j.jembe.2018.11.008

Vallée, V., Villanueva, M. C., and Blanchard, F. (2019). Functional richness and turnover patterns reveal assembly rules structuring marine fish communities on the continental shelf of French Guiana. Mar. Ecol. Prog. Ser. 630, 183-195. doi: $10.3354 /$ meps 13129

van Niekerk, L., Adams, J. B., James, N. C., Lamberth, S. J., MacKay, C. F., Turpie, J. K., et al. (2020). An Estuary Ecosystem Classification that encompasses biogeography and a high diversity of types in support of protection and management. Afr. J. Aquat. Sci. 45, 199-216. doi: 10.2989/16085914.2019.1685934

Veiga, P., Ramos-Oliveira, C., Sampaio, L., and Rubal, M. (2020). The role of urbanisation in affecting Mytilus galloprovincialis. PLOS ONE 15:e0232797. doi: 10.1371/journal.pone.0232797

Vinueza, L. R., Menge, B. A., Ruiz, D., and Palacios, D. M. (2014). Oceanographic and climatic variation drive top-down/bottom-up coupling in the Galápagos intertidal meta-ecosystem. Ecol. Monogr. 84, 411-434. doi: 10.1890/13-0169.1

Watt, C. A., and Scrosati, R. A. (2013). Bioengineer effects on understory species richness, diversity, and composition change along an environmental stress gradient: experimental and mensurative evidence. Estuar. Coast. Shelf Sci. 123, 10-18. doi: 10.1016/j.ecss.2013.02.006

Whitworth, A., Beirne, C., Pillco Huarcaya, R., Whittaker, L., Serrano Rojas, S. J., Tobler, M. W., et al. (2019). Human disturbance impacts on rainforest mammals are most notable in the canopy, especially for larger-bodied species. Divers. Distrib. 25, 1166-1178. doi: 10.1111/ddi.12930

Conflict of Interest: The authors declare that the research was conducted in the absence of any commercial or financial relationships that could be construed as a potential conflict of interest.

Copyright (c) 2020 Scrosati, Freeman and Ellrich. This is an open-access article distributed under the terms of the Creative Commons Attribution License (CC BY). The use, distribution or reproduction in other forums is permitted, provided the original author(s) and the copyright owner(s) are credited and that the original publication in this journal is cited, in accordance with accepted academic practice. No use, distribution or reproduction is permitted which does not comply with these terms. 